\title{
Influence of Mouth Pressure on Measurement of Diffusing Capacity in the Clinical Pulmonary Function Laboratory
}

\author{
David A Kaminsky and Steven C Jarzembowski
}

\begin{abstract}
BACKGROUND: Current American Thoracic Society/European Respiratory Society guidelines recommend that patients hold their breath with minimum effort at total lung capacity during measurement of the single-breath diffusing capacity of the lung for carbon monoxide $\left(\mathrm{D}_{\mathrm{LCO}}\right)$ to avoid excessively positive or negative mouth pressures. We asked to what extent do these pressures range during single-breath $D_{L C O}$ testing and whether mouth pressures are associated with singlebreath $\mathrm{D}_{\mathrm{LCO}}$. METHODS: We analyzed mouth pressures measured during clinical single-breath $D_{L C O}$ testing in an academic pulmonary function laboratory over a 3-month period. We compared mouth pressures with single-breath $\mathrm{D}_{\mathrm{LCO}}$ and determined the influence of obesity, restriction, and emphysema on mouth pressures. We used multiple linear regression to evaluate whether mouth pressure was an independent determinant of single-breath $D_{\text {LCO }}$. RESULTS: We analyzed data from 336 subjects who presented with a variety of diseases, the most common of which were unexplained dyspnea, interstitial lung disease, sarcoidosis, and emphysema. The median mouth pressure was $4.5 \mathrm{~cm} \mathrm{H}_{2} \mathrm{O}$, with a range of -13 to $31 \mathrm{~cm} \mathrm{H}_{2} \mathrm{O}$. The single-breath $\mathrm{D}_{\mathrm{LCO}}$ did not correlate with mouth pressure $(P=.08)$. There was no difference in mouth pressures between individuals with and without obesity, with and without restriction, and with and without interstitial lung disease. Mouth pressure was lower among the subjects with emphysema. There was no difference in single-breath $D_{L C O} \%$ predicted between individuals who were obese and individuals who were not obese. Multiple linear regression demonstrated that only age and $F E V_{1}$, but not mouth pressure, were independently associated with single-breath $\mathrm{D}_{\mathrm{LCO}} \%$ predicted (B-coefficient: age, $-0.35[P=.003]$; $\mathrm{FEV}_{1} \%, 0.26[P=.004]$; adjusted $\left.\mathrm{R}^{2}, \mathbf{0 . 1 6}\right)$. CONCLUSIONS: Mouth pressures varied widely during single-breath $D_{L C O}$ measurement but were not associated with the measurement of single-breath $\mathrm{D}_{\mathrm{LCO}}$ in the clinical setting of pulmonary function testing. Overall, these findings indicate that pulmonary function technologists need not discard efforts made during measurement of single-breath $\mathbf{D}_{\mathbf{L C O}}$ if only mild changes in mouth pressure occur. Key words: mouth pressure; diffusing capacity; single-breath $\mathrm{D}_{\mathrm{LCO}}$; obesity; restriction; pulmonary function testing. [Respir Care 2019;64(5):576-581. (C) 2019 Daedalus Enterprises]
\end{abstract}

\section{Introduction}

Measurement of the diffusing capacity of the lung for carbon monoxide $\left(\mathrm{D}_{\mathrm{LCO}}\right)$ by the single-breath technique is a complex, technical test that relies on highly standardized methodology to achieve valid results. One of the important aspects of the test is the condition of the breath-hold. It is well known that the Valsalva and Müller maneuvers may decrease and increase the single-breath $\mathrm{D}_{\mathrm{LCO}}$, respectively. ${ }^{1-3}$

\footnotetext{
Correspondence: David A Kaminsky MD, Pulmonary Disease and Crit-
ical Care Medicine, University of Vermont Larner College of Medicine,
Given D-213, 89 Beaumont Avenue, Burlington, VT 05405. E-mail:
david.kaminsky @uvm.edu.

Correspondence: David A Kaminsky MD, Pulmonary Disease and Crit-
ical Care Medicine, University of Vermont Larner College of Medicine,
Given D-213, 89 Beaumont Avenue, Burlington, VT 05405. E-mail:
david.kaminsky@uvm.edu.

Correspondence: David A Kaminsky MD, Pulmonary Disease and Crit-
ical Care Medicine, University of Vermont Larner College of Medicine,
Given D-213, 89 Beaumont Avenue, Burlington, VT 05405. E-mail:
david.kaminsky@ uvm.edu.

Correspondence: David A Kaminsky MD, Pulmonary Disease and Crit-
ical Care Medicine, University of Vermont Larner College of Medicine,
Given D-213, 89 Beaumont Avenue, Burlington, VT 05405. E-mail:
david.kaminsky @uvm.edu.
}

DOI: $10.4187 /$ respcare.06469

\footnotetext{
Dr Kaminsky is affiliated with the University of Vermont Larner College of Medicine, Burlington, Vermont, and Dr Jarzembowski is affiliated with the Tufts Medical Center, Boston, Massachusetts.

The study was supported by the Vermont Lung Center.

Dr Kaminsky discloses a relationship with MGC Diagnostics. Dr Jarzembowski has disclosed no conflicts of interest.
} 
Accordingly, the most recent American Thoracic Society/European Respiratory Society (ATS/ERS) 2017 guidelines, ${ }^{4}$ as well as the ATS/ERS 2005 guidelines, ${ }^{5}$ recommend that the patient maintain full inspiration at total lung capacity with minimum effort such that intrapulmonary pressure remains as close to zero as possible. However, many pulmonary function testing systems have a shutter (or valve) that closes on end-inspiration to ensure stable lung volume, and patients may exert either positive or negative pressure against the shutter, depending on whether they relax against the shutter with some force or whether they try to inspire against the shutter in an effort to hold their breath. These maneuvers may result in positive (Valsalva) or negative (Müller) mouth pressures, respectively, which may reflect intrapulmonary pressure if the glottis is open.

A recent study showed that relaxation against the valve results in a positive mouth pressure and a $3.4 \%$ lower single-breath $\mathrm{D}_{\mathrm{LCO}}$ compared with full inspiration without straining. ${ }^{6}$ However, this study was performed in healthy subjects who were specially trained to relax against the valve or to sustain full inflation without straining. Similarly, the classic studies cited about the effects of Valsalva and Müller maneuvers on the single-breath $\mathrm{D}_{\mathrm{LCO}}$ were all performed in trained healthy individuals and involved very high positive (eg, $86 \mathrm{~cm} \mathrm{H}_{2} \mathrm{O}^{2}$ ) and negative pressures (eg, $-48 \mathrm{~cm} \mathrm{H}_{2} \mathrm{O}^{1}$ ). Thus, it is unclear how relevant these studies are to the real-world conditions of clinical testing in the pulmonary function laboratory where mouth pressures may be of lesser magnitude and patients are not specially trained in the breath-hold maneuver.

To investigate the importance of mouth pressure during clinical measurement of the single-breath $\mathrm{D}_{\mathrm{LCO}}$, we recorded mouth pressures during routine single-breath $\mathrm{D}_{\mathrm{LCO}}$ measurements in all the subjects who presented to our pulmonary function laboratory over a 3-month period. Our purpose was to determine the range of pressures measured and whether they are associated with altered single-breath $\mathrm{D}_{\mathrm{LCO}}$. In particular, we were interested in examining the relationship between mouth pressure and single-breath $\mathrm{D}_{\mathrm{LCO}}$ in different disease states that are associated with altered single-breath $\mathrm{D}_{\mathrm{LCO}}$, including obesity, interstitial lung disease, and emphysema.

\section{Methods}

We conducted a retrospective, cohort study by using data obtained during routine pulmonary function testing conducted in the pulmonary function laboratory of the University of Vermont Medical Center. Data were obtained between January and March 2015, during which time we monitored mouth pressures during single-breath $\mathrm{D}_{\mathrm{LCO}}$ as part of internal quality control. Mouth pressure was displayed in real time by a virtual manometer as indicated by a moving arrow on a linear scale (Fig. 1).

\section{QUICK LOOK}

\section{Current knowledge}

Current guidelines recommend that minimum mouth pressures be maintained when measuring the singlebreath diffusing capacity of the lung for carbon monoxide. However, no data exist from the clinical pulmonary function laboratory setting to know whether this is an important concern.

\section{What this paper contributes to our knowledge}

Mouth pressures varied widely during measurement of single-breath diffusing capacity of the lung for carbon monoxide in the clinical pulmonary function laboratory but were not associated with single-breath diffusing capacity of the lung for carbon monoxide after taking into account multiple demographic and physiologic factors.

Because the arrow was rarely stationary, which indicates stable pressure, we recorded the maximum and minimum pressures, and took the mean as the final result. Only one overall mouth pressure range was recorded for each subject as determined by examination of the range across each single-breath $\mathrm{D}_{\mathrm{LCO}}$ maneuver during that testing session. All data were de-identified, and the study was approved by the University of Vermont Institutional Review Board.

We collected information on demographics, the underlying diagnosis or indication for testing, results of spirometry, and single-breath $\mathrm{D}_{\mathrm{LCO}}$ on all the subjects. In addition, some subjects also had additional testing of lung volumes and specific airway conductance, and such data were also collected. All testing was performed on a system by using a pneumotachograph for spirometry (MGC Diagnostics, St. Paul, Minnesota), gas chromatography for single-breath $\mathrm{D}_{\mathrm{LCO}}$, and body plethysmography for lung volumes and specific airway conductance. We followed the ATS/ERS standards for spirometry, ${ }^{7}$ single-breath $\mathrm{D}_{\mathrm{LCO}},{ }^{5}$ and lung volumes. ${ }^{8}$ Results were expressed as absolute values and percentage of predicted values based on reference equations for spirometry, ${ }^{9}$ lung volumes, ${ }^{10}$ and single-breath $\mathrm{D}_{\mathrm{LCO}}{ }^{11}$ that accurately depicted normal ranges in our laboratory population.

\section{Statistical Analysis}

Data were entered into a spreadsheet for statistical analysis by using JMP (SAS Institute, Cary, North Carolina). All data were analyzed for distribution and are reported as mean $\pm \mathrm{SD}$ or median (interquartile range [IQR]), depending on data distribution. Comparisons were made with 


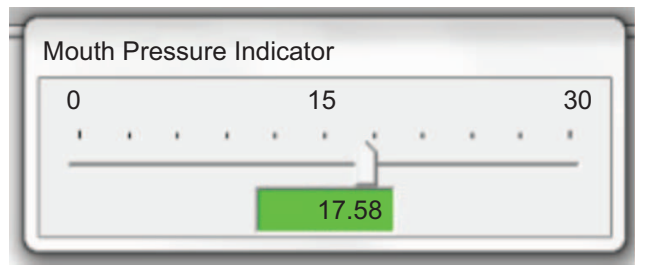

Fig. 1. Example of mouth pressure manometry reading.

unpaired $t$ tests or Wilcoxon signed-rank test, depending on data distribution. Correlations were determined by using Spearman rank-sum test. With assuming a type- 1 error rate of 0.05 and type- 2 error rate of 0.2 ( $80 \%$ power), our sample size of 336 was sufficient to detect a correlation of $\mathrm{r}=0.152$. We examined the relationship between singlebreath $\mathrm{D}_{\mathrm{LCO}}$ and its components, diffusing capacity divided by alveolar volume $\left(\mathrm{D} / \mathrm{V}_{\mathrm{A}}\right)$ and alveolar volume $\left(\mathrm{V}_{\mathrm{A}}\right)$, and mouth pressure in the entire cohort and stratified for obesity (body mass index of $>30 \mathrm{~kg} / \mathrm{m}^{2}$ ). To serve as a comparator group to the subjects who were obese, we also examined the data for those with lung-volume restriction (total lung capacity of $<80 \%$ predicted). In addition, because the population of subjects had a variety of underlying lung diseases, we also examined the data separately for 2 subgroups who would be expected to have low single-breath $\mathrm{D}_{\mathrm{LCO}}$ but, for different reasons, those with interstitial lung disease and those with emphysema. We used stepwise, backward, multiple linear regression to determine independent determinants of single-breath $\mathrm{D}_{\mathrm{LCO}}$. Statistical significance was defined for 2 -tailed $P$ values $<.05$.

\section{Results}

There were 336 subjects who had single-breath $\mathrm{D}_{\mathrm{LCO}}$ measured during the time span of our data collection (Table 1). There were an equal number of men and women overall, with approximately half current or former smokers. The most-common diagnoses listed were dyspnea (37\%), interstitial lung disease (not including idiopathic pulmonary fibrosis) (23\%), sarcoidosis (13\%), emphysema (9\%), asthma (5\%), idiopathic pulmonary fibrosis $(5 \%)$, connective tissue disease (4\%), COPD (not emphysema) (3\%), and multiple other diagnoses ( $<1 \%$ each). There was a similar distribution of underlying diseases among the participants who were obese and those who were not obese, except for a higher prevalence of asthma (61 vs $39 \%$ ), and a lower prevalence of sarcoidosis (33 vs 67\%) and idiopathic pulmonary fibrosis (28 vs $72 \%$ ) in the subjects who were obese.

The median mouth pressure among all the individuals was $4.5 \mathrm{~cm} \mathrm{H}_{2} \mathrm{O}$, with a broad range, from -13 to $31 \mathrm{~cm} \mathrm{H}_{2} \mathrm{O}$ (Fig. 2). The single-breath $\mathrm{D}_{\mathrm{LCO}}$ did not correlate with mouth pressure $P=.08$ (Fig. 3) but $\mathrm{D} / \mathrm{V}_{\mathrm{A}}$ did, albeit weakly (Spearman rho $=0.14, P=.01$ ). There was no difference in mouth pressures between the individuals who were obese and individuals who were not obese. There was no difference in single-breath $\mathrm{D}_{\mathrm{LCO}} \%$ predicted between individuals who were obese and individuals who were not obese, but there was a weak association of singlebreath $\mathrm{D}_{\mathrm{LCO}} \%$ predicted with body mass index, which was not statistically significant (Spearman rho $=0.10$ $(P=.060)$ (Fig. 4). However, D/V $\mathrm{A}$ was higher and $\mathrm{V}_{\mathrm{A}}$ was lower in the subjects with obesity, and these parameters correlated with body mass index $\left(\mathrm{D} / \mathrm{V}_{\mathrm{A}}\right.$ vs. obesity: Spearman rho $=0.22[P<.001]$, and $\mathrm{V}_{\mathrm{A}}$ vs. obesity: Spearman rho $=-0.13[P=.01])$.

Because we assumed that obesity would act to amplify any positive or negative mouth pressure because of the effect of the heavy chest wall, we also examined whether mouth pressures differed between those with restriction (total lung capacity of $<80 \%$ predicted) and those without restriction. We reasoned that, if there was an effect of obesity on mouth pressure due to restriction, then we should see different mouth pressures between those with and those without restriction. In this smaller subset who had lung volumes measured ( $n=95)$, median (IQR) mouth pressures were similar between those with and those without restriction $($ restriction $=6.0[3.5-13.4])$ vs no restriction $=$ $\left.4.5[1.5-10.0]) \mathrm{cm} \mathrm{H}_{2} \mathrm{O}, P=.26\right)$. The same was true if we examined restriction versus no restriction only among the individuals who were not obese $(n=45)$ (median $[\mathrm{IQR}]$; restriction $=5.5[2.6-10.2]$ vs no restriction $=3.9$ [1.0-8.5] $\mathrm{cm} \mathrm{H}_{2} \mathrm{O}, P=.49$ ).

Likewise, because the underlying disease may be a strong determinant of single-breath $\mathrm{D}_{\mathrm{LCO}}$, we also compared the mouth pressures and single-breath $\mathrm{D}_{\mathrm{LCO}}$ among those with interstitial lung disease versus the rest of the study population. We reasoned that the single-breath $\mathrm{D}_{\mathrm{LCO}}$ was likely to be lower among those with interstitial lung disease, so if the mouth pressures were similar, then any differences in single-breath $\mathrm{D}_{\mathrm{LCO}}$ were likely due to the underlying disease only. Indeed, we found that the mean \pm SD singlebreath $\mathrm{D}_{\mathrm{LCO}}$ was lower among this group compared with the rest of the study population (interstitial lung disease $=$ $61.6 \pm 18.2$ vs rest of population $=74.1 \pm 20.0 \%$ predicted, $P=<.001$ ), but the median (IQR) mouth pressures were equivalent ( interstitial lung disease $=4.65[1.65-$ 8.75] vs rest of population $=4.5[1.5-10] \mathrm{cm} \mathrm{H}_{2} \mathrm{O}, P=.91$ ).

Similarly, we compared those with emphysema $(n=29)$ with the rest of the study population, again reasoning that the single-breath $\mathrm{D}_{\mathrm{LCO}}$ should be lower among this subset of subjects. This time, despite a lower mean \pm SD singlebreath $\mathrm{D}_{\mathrm{LCO}}$ (emphysema $=50.8 \pm 12.6$ vs rest of population $=72.5 \pm 19.9] \%$ predicted, $P<.001)$, the median (IQR) mouth pressures among those with emphysema were also lower (emphysema $=2.0[0.5-5.5]$ vs rest of population $\left.=4.6[1.6-10] \mathrm{cm} \mathrm{H}_{2} \mathrm{O}, P=.005\right)$. When 
Table 1. Demographics and Pulmonary Function of the Study Population

\begin{tabular}{|c|c|c|c|c|}
\hline Characteristic & All Subjects & $\begin{array}{l}\text { Subjects Who } \\
\text { Were Obese }\end{array}$ & $\begin{array}{c}\text { Subjects Who } \\
\text { Were Not Obese }\end{array}$ & $\begin{array}{c}P \text { (Obese } \\
\text { vs Not Obese) }\end{array}$ \\
\hline Age, mean \pm SD y & $62 \pm 15$ & $62 \pm 12$ & $61 \pm 17$ & .55 \\
\hline Female/male, $\%$ & $52 / 48$ & $61 / 39$ & $44 / 56$ & .002 \\
\hline $\mathrm{BMI}$, mean $\pm \mathrm{SD} \mathrm{kg} / \mathrm{m}^{2}$ & $30 \pm 6.6$ & $36 \pm 5$ & $25 \pm 3$ & \\
\hline Any smoking, $\%$ & 56 & 61 & 51 & .07 \\
\hline Pack-years, mean $\pm \mathrm{SD}$ & $20 \pm 30$ & $24 \pm 32$ & $16 \pm 27$ & .032 \\
\hline $\mathrm{FEV}_{1}$, mean $\pm \mathrm{SD} \%$ predicted & $80 \pm 21$ & $78 \pm 21$ & $81 \pm 21$ & .16 \\
\hline $\mathrm{FVC}$, mean $\pm \mathrm{SD} \%$ predicted & $80 \pm 18$ & $77 \pm 18$ & $83 \pm 19$ & .001 \\
\hline $\mathrm{FEV}_{1} / \mathrm{FVC}$, mean $\pm \mathrm{SD}$ & $0.76 \pm 0.13$ & $0.77 \pm 0.12$ & $0.74 \pm 0.13$ & .02 \\
\hline Single-breath $\mathrm{D}_{\mathrm{LCO}}$, mean $\pm \mathrm{SD} \%$ predicted & $71 \pm 20$ & $72 \pm 20$ & $70 \pm 20$ & .41 \\
\hline $\mathrm{D} / \mathrm{V}_{\mathrm{A}}$, median $(\mathrm{IQR}) \%$ predicted & $96(77-116)$ & $100(82-120)$ & $93(75-112)$ & .01 \\
\hline $\mathrm{V}_{\mathrm{A}}$, mean $\pm \mathrm{SD} \%$ predicted & $74 \pm 18$ & $72 \pm 17$ & $76 \pm 19$ & .035 \\
\hline $\mathrm{TLC}$, mean $\pm \mathrm{SD} \%$ predicted & $90 \pm 19$ & $88 \pm 18$ & $92 \pm 20$ & .39 \\
\hline FRC, mean $\pm \mathrm{SD} \%$ predicted & $92 \pm 22$ & $88 \pm 22$ & $100 \pm 22$ & .009 \\
\hline $\mathrm{RV}$, median (IQR) \% predicted & $104(79-122)$ & $99(77-113)$ & $112(84-124)$ & .08 \\
\hline $\mathrm{RV} / \mathrm{TLC}$, mean $\pm \mathrm{SD}$ & $41 \pm 10$ & $0.41 \pm 0.10$ & $0.42 \pm 0.10$ & .85 \\
\hline $\mathrm{sG}_{\mathrm{aw}}$, median $(\mathrm{IQR}) \mathrm{cm}\left([\mathrm{L} / \mathrm{s}] / \mathrm{cm} \mathrm{H} \mathrm{H}_{2} \mathrm{O}\right) / \mathrm{L}$ & $0.20(0.14-0.24)$ & $0.21(0.17-0.26)$ & $0.17(0.12-0.23)$ & .03 \\
\hline Mouth pressure, median (IQR) $\mathrm{cm} \mathrm{H}_{2} \mathrm{O}$ & $4.5(1.5-9.8)$ & $4.42(1.5-10)$ & $4.65(1.5-9.0)$ & .98 \\
\hline $\begin{array}{l}\mathrm{BMI}=\text { body mass index } \\
\mathrm{D}_{\mathrm{LCO}}=\text { diffusing capacity of the lung for carbon monoxide } \\
\mathrm{D} / \mathrm{V}_{\mathrm{A}}=\text { diffusing capacity divided by alveolar volume } \\
\mathrm{IQR}=\text { interquartile range }(25 \text { th }-75 \text { th percentiles) } \\
\mathrm{V}_{\mathrm{A}}=\text { alveolar volume } \\
\mathrm{TLC} \text { = total lung capacity } \\
\mathrm{FRC} \text { = functional residual capacity } \\
\mathrm{RV}=\text { residual volume } \\
\mathrm{sG}_{\mathrm{aw}}=\text { specific conductance of the airways }\end{array}$ & & & & \\
\hline
\end{tabular}

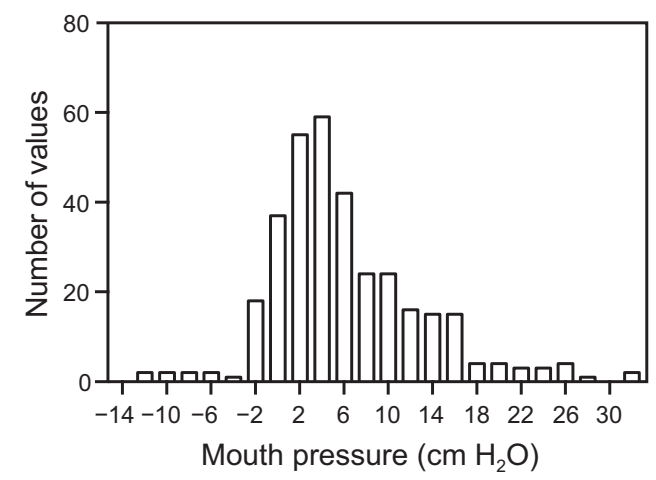

Fig. 2. Distribution of mouth pressures.

using stepwise backward multiple linear regression by entering age, sex, body mass index, mouth pressure, and all spirometry and lung-volume parameters, only age and $\mathrm{FEV}_{1}$ were independently associated with single-breath $\mathrm{D}_{\mathrm{LCO}} \%$ predicted ( $ß$-coefficient: age, $-0.35[P=.003]$; $\mathrm{FEV}_{1} \%$, $0.26[P=.004]$; adjusted $\left.\mathrm{R}^{2}, 0.16\right)$. Thus, mouth pressure was not an independent determinant of single-breath $\mathrm{D}_{\mathrm{LCO}}$.

\section{Discussion}

The results of this study showed that there was a wide range of mouth pressures recorded during routine clinical

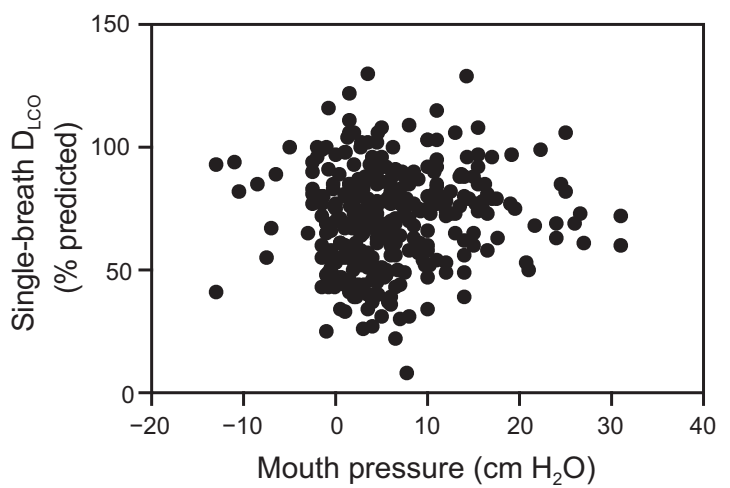

Fig. 3. Single-breath diffusing capacity of the lung for carbon monoxide $\left(D_{\text {LCO }}\right)$ versus mouth pressure.

testing, with an overall median positive pressure $\left(4.5 \mathrm{~cm} \mathrm{H}_{2} \mathrm{O}\right)$, despite coaching to maintain a mouth pressure as close to zero as possible. In addition, mouth pressure did not correlate with single-breath $\mathrm{D}_{\mathrm{LCO}}$. This indicated that, even though it is of technical concern, there was no apparent effect of a small, non-zero mouth pressure on single-breath $\mathrm{D}_{\mathrm{LCO}}$. As stated previously, earlier studies of the effects of Valsalva and Müller maneuvers during the breath-hold time of the single-breath $\mathrm{D}_{\mathrm{LCO}}$ test demonstrated significant changes in single-breath $\mathrm{D}_{\mathrm{LCO}}$; the mechanism of such effects is thought 


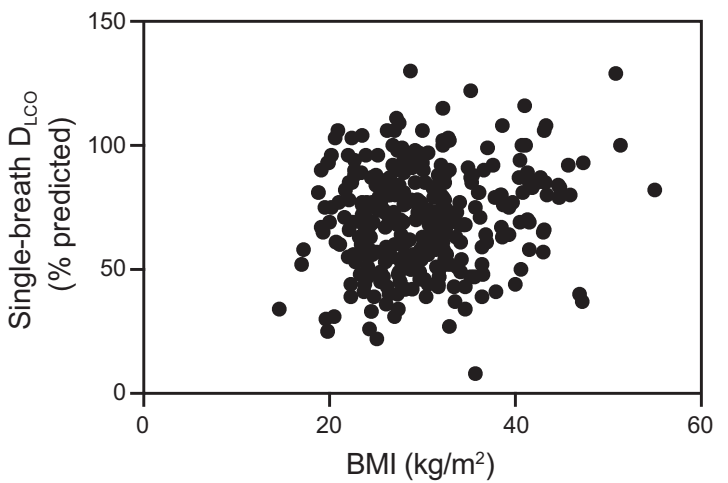

Fig. 4. Single-breath diffusing capacity of the lung for carbon monoxide $\left(D_{\text {LCO }}\right)$ versus body mass index (BMI).

to be related to the changes in intrathoracic pressure that accompany these maneuvers. ${ }^{1-3}$

During a Valsalva maneuver, attempting to expire against a closed glottis results in an increase in intrathoracic pressure, which would reduce venous return and, hence, pulmonary capillary blood volume during the breath-hold period, which results in a decrease in single-breath $\mathrm{D}_{\mathrm{LCO}}$. During a Müller maneuver, attempting to inspire against a closed glottis results in a negative intrathoracic pressure, which would increase venous return and, hence, pulmonary capillary blood volume during the breath-hold period, which results in an increase in single-breath $\mathrm{D}_{\mathrm{LCO}}$. However, it is important to note that, in studies of these effects, the pressures involved were quite a bit higher than those observed in this study. ${ }^{1-3}$

A more-recent study showed that there was a $3.4 \%$ decrease in the single-breath $\mathrm{D}_{\mathrm{LCO}}$ when trained volunteers relaxed against the closed shutter and generated an average positive pressure of $14 \mathrm{~cm} \mathrm{H}_{2} \mathrm{O} .{ }^{6}$ This, again, was higher than the average pressure seen in our study, although the range in our study extended to $30 \mathrm{~cm} \mathrm{H}_{2} \mathrm{O}$. We suspect that the lack of association between mouth pressure and single-breath $\mathrm{D}_{\mathrm{LCO}}$ in the current study may have been due to the relatively low range of mouth pressures measured. However, there was no correlation of mouth pressure with single-breath $\mathrm{D}_{\mathrm{LCO}}$, which we acknowledge may be importantly influenced by the fact that all the subjects in this study were referred for lung function testing due to symptoms; accordingly, many would have had underlying lung disease, which would likely be the main influence on their single-breath $\mathrm{D}_{\mathrm{LCO}}$. Thus, we were not able to isolate the independent effect of mouth pressure on single-breath $\mathrm{D}_{\mathrm{LCO}}$. Nevertheless, given the findings of this study, we suggested that, in the setting of clinical testing, the influence of mouth pressure was likely not clinically important compared with the influence of the underlying pulmonary condition. These findings indicate that single-breath $\mathrm{D}_{\mathrm{LCO}}$ measurements remain valid in the setting of the relatively low pressures $\left(-13\right.$ to $30 \mathrm{~cm} \mathrm{H}_{2} \mathrm{O}$ ) we measured in this study that might be expected with mild Müller or Valsalva maneuvers.

Given that there were many factors that could have influenced single-breath $\mathrm{D}_{\mathrm{LCO}}$, including an underlying disease state, we examined 2 situations in which singlebreath $\mathrm{D}_{\mathrm{LCO}}$ should have been lower to determine if mouth pressures were also different. In the case of interstitial lung disease, there was no difference in mouth pressure among this subgroup compared with the whole population, despite a lower single-breath $\mathrm{D}_{\mathrm{LCO}}$, which indicated that the lower single-breath $\mathrm{D}_{\mathrm{LCO}}$ was associated with the disease state and not the mouth pressure. In the case of emphysema, mouth pressure was lower in the setting of this subgroup, having a lower single-breath $\mathrm{D}_{\mathrm{LCO}}$, but, interestingly, this was in the opposite direction of what one would predict, because lower positive mouth pressures, if reflective of intrapulmonary pressure, should have resulted in a higher single-breath $\mathrm{D}_{\mathrm{LCO}}$ (less of a Valsalva effect). The lower mouth pressures in this case likely reflected the reduced elastic recoil of the lung when such subjects were relaxing against the closed shutter during the breath-hold. Accordingly, because the single-breath $\mathrm{D}_{\mathrm{LCO}}$ was lower, not higher, again we suspected that mouth pressure was not a determining factor in the single-breath $\mathrm{D}_{\mathrm{LCO}}$. Also, we entered mouth pressure into a multiple linear regression model, including all demographic, spirometry, and lung-volume variables but were unable to demonstrate that mouth pressure was an independent determinant of singlebreath $\mathrm{D}_{\mathrm{LCO}}$.

In our study, the subjects who were obese had similar single-breath $\mathrm{D}_{\mathrm{LCO}}$ but higher $\mathrm{D} / \mathrm{V}_{\mathrm{A}}$ and lower $\mathrm{V}_{\mathrm{A}}$ compared with subjects who were not obese, similar to the findings of Enache et al. ${ }^{12}$ In obese individuals, multiple studies described both an increase ${ }^{13,14}$ or decrease ${ }^{15,16}$ in the single-breath $\mathrm{D}_{\mathrm{LCO}}$. Of note, the study by Saydain et al ${ }^{14}$ defined an increased single-breath $\mathrm{D}_{\mathrm{LCO}}$ as $>140 \%$ predicted, and none of our subjects had single-breath $\mathrm{D}_{\mathrm{LCO}}$ measurements this high. The mechanism for such an increase is unclear but has been ascribed to an increase in pulmonary capillary blood volume from increased total blood volume associated with obesity. ${ }^{17}$

As part of this study, we assessed whether mouth pressures were different between participants who were obese and participants who were not obese to determine whether this technical factor might account for the association of obesity with an elevated single-breath $\mathrm{D}_{\mathrm{LCO}}$. In particular, to explain a higher single-breath $\mathrm{D}_{\mathrm{LCO}}$ in obesity, intrathoracic pressure would need to be more negative in subjects who were obese, but we found no difference in mouth pressure or single-breath $\mathrm{D}_{\mathrm{LCO}}$ between the subjects who were obese and the subjects who were not obese. Interestingly, when we examined mouth pressures in restricted subjects, we did not find them to be increased or decreased compared with the subjects who were not restricted, 
regardless of whether they were obese, so if obesity were to affect mouth pressures, then analysis of our data indicated that this would not be due to any restrictive aspect of obesity. However, our results cannot be directly compared with those of other studies because other studies involved people who were obese but otherwise healthy and approximately half of the subjects in our study with obesity had concomitant lung disease (eg, interstitial lung disease or emphysema), which would confound the results.

\section{Limitations}

Our results must be interpreted with certain limitations in mind. First, as previously stated, we were not able to isolate the effect of mouth pressure alone on single-breath $\mathrm{D}_{\mathrm{LCO}}$ because of the multitude of diseases included in our population. However, examination of those with interstitial lung disease and emphysema indicated that mouth pressures were not important determinants of the single-breath $\mathrm{D}_{\mathrm{LCO}}$. Nevertheless, a prospective study that examined the effect of changing mouth pressure on single-breath $\mathrm{D}_{\mathrm{LCO}}$ within individuals would have provided more specific information. Second, mouth pressure measurement was not stable in all individuals, so there may be some error in its accurate measurement. Third, we could not be sure that the subjects kept their glottis open during the breath-hold, which is essential to assuming that mouth pressure reflected intrapulmonary pressure. Fourth, because not all of the subjects had single-breath $\mathrm{D}_{\mathrm{LCO}}$ adjusted for hemoglobin, some of the single-breath $\mathrm{D}_{\mathrm{LCO}}$ values may have been inaccurate if the subjects had anemia or, less commonly, erythrocytosis. However, a recent study showed that only a small proportion $(<10 \%)$ of the subjects had a change in interpretation of single-breath $\mathrm{D}_{\mathrm{LCO}}$ after adjustment for hemoglobin. ${ }^{18}$ Fifth, the results necessarily only apply to populations similar to ours, which is representative of our community but may not reflect the demographics or disease states found elsewhere. Nevertheless, we had a relatively large population with a diversity of underlying lung disease.

\section{Conclusions}

We demonstrated that mouth pressures varied widely during single-breath $\mathrm{D}_{\mathrm{LCO}}$ measurement but these did not seem to be associated with the measurement of single-breath $\mathrm{D}_{\mathrm{LCO}}$ in the clinical setting of pulmonary function testing. This is despite the importance of excessive positive and negative intrapulmonary pressure on the single-breath $\mathrm{D}_{\mathrm{LCO}}$ when examined in isolation. We found no indication that mouth pressures influenced the single-breath $\mathrm{D}_{\mathrm{LCO}}$ in obesity. Overall, analysis of these findings indicates that pulmonary function technologists need not discard efforts made during measurement of single-breath $\mathrm{D}_{\mathrm{LCO}}$ if only mild Müller or Valsalva maneuvers are observed.

\section{ACKNOWLEDGMENT}

The authors thank Jeffrey M Haynes, who provided thoughtful comments on the manuscript.

\section{REFERENCES}

1. Cotton DJ, Mink JT, Graham BL. Effect of high negative inspiratory pressure on single breath CO diffusing capacity. Respir Physiol 1983; 54(1):19-29.

2. Smith TC, Rankin J. Pulmonary diffusing capacity and the capillary bed during Valsalva and Muller maneuvers. J Appl Physiol 1969; 27(6):826-833.

3. Suzuki S, Numata H, Okubo T. Effect of alveolar pressure on singlebreath CO diffusing capacity at mid-lung volume. Respir Physiol 1990;81(3):313-320.

4. Graham BL, Brusasco V, Burgos F, Cooper BG, Jensen R, Kendrick A, et al. 2017 ERS/ATS standards for single-breath carbon monoxide uptake in the lung. Eur Respir J 2017;49(1). pii: 1600016.

5. Macintyre N, Crapo RO, Viegi G, Johnson DC, van der Grinten CP, Brusasco V, et al. Standardisation of the single-breath determination of carbon monoxide uptake in the lung. Eur Respir J 2005;26(4): 720-735.

6. Normand H, Lavigne F, Mouadil A. Performing the apnea of the single-breath carbon monoxide diffusing capacity: relaxation on the shutter or full inspiration with near atmospheric intrapulmonary pressure? Chest 2006;130(1):207-213.

7. Miller MR, Hankinson J, Brusasco V, Burgos F, Casaburi R, Coates A, et al.; ATS/ERS Task Force. Standardisation of spirometry. Eur Respir J 2005;26(2):319-338.

8. Wanger J, Clausen JL, Coates A, Pedersen OF, Brusasco V, Burgos F, et al. Standardisation of the measurement of lung volumes. Eur Respir J 2005;26(3):511-522.

9. Hankinson JL, Odencrantz JR, Fedan KB. Spirometric reference values from a sample of the general U.S. population. Am J Respir Crit Care Med 1999;159(1):179-187.

10. Goldman HI, Becklake MR. Respiratory function tests; normal values at median altitudes and the prediction of normal results. Am Rev Tuberc 1959;79(4):457-467.

11. Gaensler EA, Smith AA. Attachment for automated single breath diffusing capacity measurement. Chest 1973;63(2):136-145.

12. Enache I, Oswald-Mammosser M, Scarfone S, Simon C, Schlienger JL, Geny B, Charloux A. Impact of altered alveolar volume on the diffusing capacity of the lung for carbon monoxide in obesity. Respiration 2011;81(3):217-222.

13. Collard P, Wilputte JY, Aubert G, Rodenstein DO, Frans A. The single-breath diffusing capacity for carbon monoxide in obstructive sleep apnea and obesity. Chest 1996;110(5):1189-1193.

14. Saydain G, Beck KC, Decker PA, Cowl CT, Scanlon PD. Clinical significance of elevated diffusing capacity. Chest 2004;125(2):446452.

15. Biring MS, Lewis MI, Liu JT, Mohsenifar Z. Pulmonary physiologic changes of morbid obesity. Am J Med Sci 1999;318(5):293-297.

16. Ray CS, Sue DY, Bray G, Hansen JE, Wasserman K. Effects of obesity on respiratory function. Am Rev Respir Dis 1983;128(3): 501-506.

17. Oppenheimer BW, Berger KI, Rennert DA, Pierson RN, Norman RG, Rapoport DM, et al. Effect of circulatory congestion on the components of pulmonary diffusing capacity in morbid obesity. Obesity (Silver Spring) 2006;14(7):1172-1180.

18. Haynes JM, Ruppel GL, Kaminsky DA. Impact of hemoglobin and carboxyhemoglobin adjustment on the interpretation of pulmonary diffusing capacity in a general population. Chest 2017;151(5):11881189. 